\title{
FUNDO DE AMPARO AO TRABALHADOR CONSTITUCIONAL: CONCEITOS, ESTATÍSTICAS E IMPACTOS ${ }^{1}$
}

Davi Botelho

\section{SINOPSE}

O objetivo deste trabalho é descrever o Fundo de Amparo ao Trabalhador (FAT) Constitucional conceitual e descritivamente, além de trazer algumas estimativas de seus impactos sobre a economia. O FAT Constitucional, parcela do FAT destinada por legislação ao financiamento de programas de desenvolvimento econômico, é uma das fontes mais importantes, seguras e regulares do Banco Nacional de Desenvolvimento Econômico e Social (BNDES). Para se ilustrar a atuação do FAT Constitucional, são utilizados dados das operaçóes não automáticas das contrataçóes do BNDES entre 2002 e abril de 2021, ficando constatado que 70\% destes projetos possuem alguma participação do FAT Constitucional como fonte de recursos e, deste percentual, 43\% financiaram projetos de infraestrutura. Diante das estimativas do BNDES, o FAT Constitucional gerou ou manteve 12 milhóes de empregos entre 2007 e 2020.

Palavras-chave: FAT constitucional; BNDES; fonte de recursos; geração de empregos.

\section{INTRODUÇÃO}

$\mathrm{Na}$ literatura sobre bancos públicos e desenvolvimento econômico no Brasil, é comum encontrar estudos sobre a destinação dos recursos do Banco Nacional de Desenvolvimento Econômico e Social (BNDES) e os impactos causados pelos seus financiamentos na produtividade das empresas apoiadas; e sobre a geração de emprego e renda. No entanto, Prochnik e Machado (2008) salientam que os instrumentos de captação e as fontes de recursos que possibilitam a atuação do banco são pouco estudados.

Dentre as fontes de recurso do BNDES, merece destaque o Fundo de Amparo ao Trabalhador (FAT) Constitucional, de natureza compulsória, que se configura como fonte automática e segura de recursos para o BNDES (Prochnik e Machado, 2008). Em virtude do papel atribuído ao FAT Constitucional, o objetivo deste texto é realizar um levantamento conceitual dessa fonte, apresentar algumas estatísticas descritivas dos projetos financiados por esse fundo e iniciar uma discussáo acerca dos impactos gerados por esses projetos sobre o desenvolvimento econômico, especialmente em relação à geração de emprego. 


\section{O FAT}

Regulamentado pela Lei no 7.998 , de 11 de janeiro de 1990, o FAT teve sua origem no art. 239 da Constituição Federal promulgada em 1988, que estabeleceu que pelo menos $40 \%$ dos recursos do fundo seriam direcionados ao financiamento de programas de desenvolvimento econômico, a cargo do BNDES. A outra parcela de $60 \%$ seria destinada ao financiamento do Programa do Seguro-Desemprego e ao abono salarial.

O FAT é um fundo contábil, de natureza financeira e possui por finalidade: i) o custeio do Programa do Seguro-Desemprego; ii) o pagamento do abono salarial; iii) o financiamento de programas de educação profissional e tecnológica; e iv) o aporte ao desenvolvimento econômico. Os recursos do FAT são constituídos, majoritariamente, pela arrecadação das contribuiçóes devidas ao Programa de Integraçáo Social (PIS) e ao Programa de Formaçáo do Patrimônio do Servidor Público (Pasep) e pelo pagamento dos juros e da correção monetária pelos agentes aplicadores dos recursos do fundo.

O FAT é gerido pelo Conselho Deliberativo do Fundo de Amparo ao Trabalhador (Codefat), órgão colegiado, também instituído pela lei do FAT, sendo composto por representantes de trabalhadores, empregadores, órgáos e entidades governamentais. Das competências atribuídas ao Codefat, de acordo com Santos (2006), vale destacar a elaboração de diretrizes para programas e para a alocação de recursos, o acompanhamento e a avaliaçáo do impacto social, o aperfeiçoamento da legislação referente às políticas públicas de emprego e renda, e a fiscalização da administraçáo do FAT.

Silva (2019) qualifica o FAT como um mecanismo de financiamento que atua em dois sentidos diferentes por meio da mesma fonte. Por um lado, está a proteção social de trabalhadores desempregados e de baixa renda; e, por outro, a disponibilização de recursos para apoiar projetos de desenvolvimento econômico, o que também favorece a geraçáo de novos empregos e a ampliação da renda.

\section{O FAT CONSTITUCIONAL}

Como mencionado, uma parcela de $40 \%$ da arrecadaçáo do FAT seria destinada ao financiamento de programas ou projetos de desenvolvimento econômico via transferência de recursos, com critérios de remuneração do fundo. Essa parcela é chamada de FAT Constitucional, que visa estimular a criação de empregos e ampliação de renda por intermédio do financiamento a longo prazo de projetos operacionalizados pelo BNDES.

Também denominado de recursos ordinários, o FAT Constitucional consiste em uma fonte permanente e segura, com custos compatíveis para o financiamento de longo prazo de investimentos em atividades produtivas, além de ser uma das principais captaçóes de recursos do BNDES (Santos, 2006). No entanto, uma alteração na legislação por meio da Emenda Constitucional no 103/2019 determinou a reduçáo no percentual de recursos do FAT repassados ao BNDES, de $40 \%$ para $28 \%$.

$\mathrm{Na}$ época de sua criação, o FAT Constitucional solucionou o problema da falta de regularidade das fontes de recursos do BNDES, que dificultava a instituição de planejar sua atuação. O fundo também representou um avanço significativo na consolidação de uma política de financiamento aos programas de desenvolvimento econômico no Brasil (Monteiro Neto, 2012). Silva (2019) ressalta o importante papel do FAT Constitucional de constituir uma base para operaçôes de crédito voltada a investimentos e capital de giro de empresas públicas e privadas.

Em conjunto, o FAT e o Tesouro Nacional constituem a maior parcela da fonte de recursos do BNDES, sendo complementados por outros fundos governamentais, além de captaçôes no exterior, emissóes públicas e instrumentos bancários (BNDES, 2021). Em relação a essa composição, o FAT representou $29 \%$ da estrutura de 
funding do BNDES em 2017, alcançou 36\% em 2018 e, em 2019 e 2020, esse percentual variou entre 42\% e $43 \%$. No primeiro trimestre de 2021 , o FAT atingiu 46\%, confirmando uma tendência de crescimento relativo na composição de recursos captados pelo banco.

Uma característica importante do FAT Constitucional é o fato de seu prazo de exigibilidade do saldo devedor ser indefinido. O BNDES não tem que cumprir um cronograma preestabelecido de devolução do principal, cabendo apenas o pagamento periódico de juros, que é feito semestralmente (janeiro e julho). No entanto, existe uma ressalva: caso haja insuficiência de recursos para o pagamento do seguro-desemprego e do abono salarial, os recursos alocados no FAT Constitucional podem ser resgatados; por isso, o FAT Constitucional é também denominado de dívida subordinada (Monteiro Neto, 2012; Silva, 2019).

Em relação ao pagamento dos juros sobre o saldo do FAT Constitucional, os recursos aplicados pelo BNDES, no caso dos financiamentos concedidos em reais, são remunerados pela Taxa de Longo Prazo (TLP) para as contrataçóes realizadas a partir de $1^{\circ}$ de janeiro de 2018 e pela Taxa de Juros de Longo Prazo (TJLP) para as operaçóes contratadas até 31 de dezembro de 2017. No caso dos financiamentos concedidos em moeda estrangeira, os recursos são remunerados pela Taxa de Juros para Empréstimos e Financiamentos no Mercado Interbancário de Londres (Libor). Os recursos disponíveis, por sua vez, são remunerados pela taxa média ajustada dos financiamentos diários apurados no Sistema Especial de Liquidação e de Custódia (Selic) para títulos públicos federais (Santos, 2006; BNDES, 2021).

Outro aspecto do FAT Constitucional é que cabe ao BNDES decidir em quais programas de desenvolvimento econômico os recursos serão aplicados, respeitando as normas operacionais do banco (Santos, 2006). Portanto, o Codefat não possui competência para estabelecer diretrizes e parâmetros para a alocação do FAT Constitucional (Monteiro Neto, 2012).

Além dos repasses constitucionais, o BNDES capta recursos no FAT na forma denominada Depósitos Especiais para atender a programas e linhas de crédito específicos. Nesta modalidade, os recursos não são exclusivos ao BNDES, podendo ser destinados a outras instituiçôes financeiras federais. Além disso, as aplicaçóes do FAT Depósitos Especiais possuem prazo de exigibilidade definido e devem seguir as diretrizes estabelecidas pelo Codefat, que define setores e portes de empresas a serem apoiados, além de parâmetros como taxas de juros e prazos dos empréstimos. Essas características são reportadas por Tinoco, Borça Junior e Macedo (2018) como as principais diferenças em relação ao FAT Constitucional.

\subsection{Estatísticas descritivas do FAT Constitucional}

Para ilustrar uma breve descrição do perfil dos projetos e empresas apoiados pelo BNDES com recursos do FAT Constitucional, são utilizados os microdados das operaçóes contratadas na forma direta e indireta não automática no período que se inicia em 2002 e se estende até o primeiro quadrimestre de 2021. Destes contratos, cabe destacar que 49,5\% estão ativos e, em média, as empresas apoiadas possuem 21 meses de carência e 90 meses de amortização.

Durante o período analisado, o FAT Constitucional financiou 13.528 projetos; em termos relativos, esse número representa $69,3 \%$ de todos os empréstimos operacionalizados pelo BNDES. Vale mencionar que um projeto pode conter mais de uma origem de recursos e que apenas 18,2\% são exclusivamente financiados pelo FAT Constitucional.

Do total de projetos financiados pelo FAT Constitucional no período, o setor ${ }^{3}$ de infraestrutura contou com o maior quantitativo (43,3\%), seguido pelo setor industrial (36,4\%). O setor de comércio e serviços e o da

3. O setor é um agrupamento utilizado pelo BNDES para fins estatísticos, levando em consideração o código da Classificação Nacional de Atividades Econômicas (CNAE) da empresa e os produtos do BNDES. 
agropecuária concentraram, respectivamente, $16,5 \%$ e 3,8\% do total de projetos. Aproximadamente metade dos projetos se enquadram na área operacional ${ }^{4}$ de indústria e serviços $(49,0 \%)$ e aqueles na área de energia totalizaram $28,7 \%$, acompanhados pelas áreas de gestáo pública e socioambiental (10,9\%), saneamento e transporte $(10,7 \%)$ e operaçóes e canais digitais $(0,6 \%)$.

Em relação ao porte, as grandes empresas reuniram quase a totalidade das contrataçóes, em torno de 93,6\%; as médias registraram 4,4\%; as pequenas e microempresas, $2,0 \%$. Observou-se, segundo a natureza do contratante, que $90,6 \%$ dos projetos apoiados pelo FAT Constitucional foram direcionados para o setor privado, enquanto as administraçôes direta e indireta receberam $5,6 \%$ e 3,6\%, respectivamente.

\subsection{Impactos do FAT Constitucional}

Como enfatizado ao longo do texto, o repasse de uma parcela do FAT ao BNDES para o financiamento de projetos a longo prazo visa à geração de oportunidades de trabalho e ampliação da renda. Uma das formas de quantificar os impactos causados pelas açôes proporcionadas pelo FAT Constitucional é a estimação dos postos de trabalhos gerados ou mantidos realizada pelo BNDES seguindo uma metodologia própria, o Modelo de Geração de Empregos (MGE).

O MGE do BNDES, de acordo com a metodologia criada por Najberg e Ikeda (1999), se baseia em dados do Sistema de Contas Nacionais (SCN), do Instituto Brasileiro de Geografia e Estatística (IBGE), e em sua matriz de insumo-produto (MIP) para quantificar os empregos gerados a partir de um aumento da demanda final em cada setor da economia. Os resultados do MGE devem ser interpretados, como ressalta Santos (2018), como o número médio de postos de trabalho requerido para viabilizar a implantação dos investimentos apoiados pelo BNDES.

As estimativas do número total de empregos gerados ou mantidos são observadas, em um período mais recente, no gráfico 1. De 2007 a 2020, foram gerados/mantidos 11,8 milhóes de empregos - destes, 6,7 milhóes de forma direta e 5,1 milhôes de forma indireta -, sendo que, de 2011 a 2013, são observados os valores mais expressivos da série, registrando 3,3 milhóes de empregos gerados/mantidos.

\section{GRÁFICO 1}

Empregos gerados ou mantidos pelos desembolsos do FAT Constitucional (2007-2020)

(Em 1 mil)

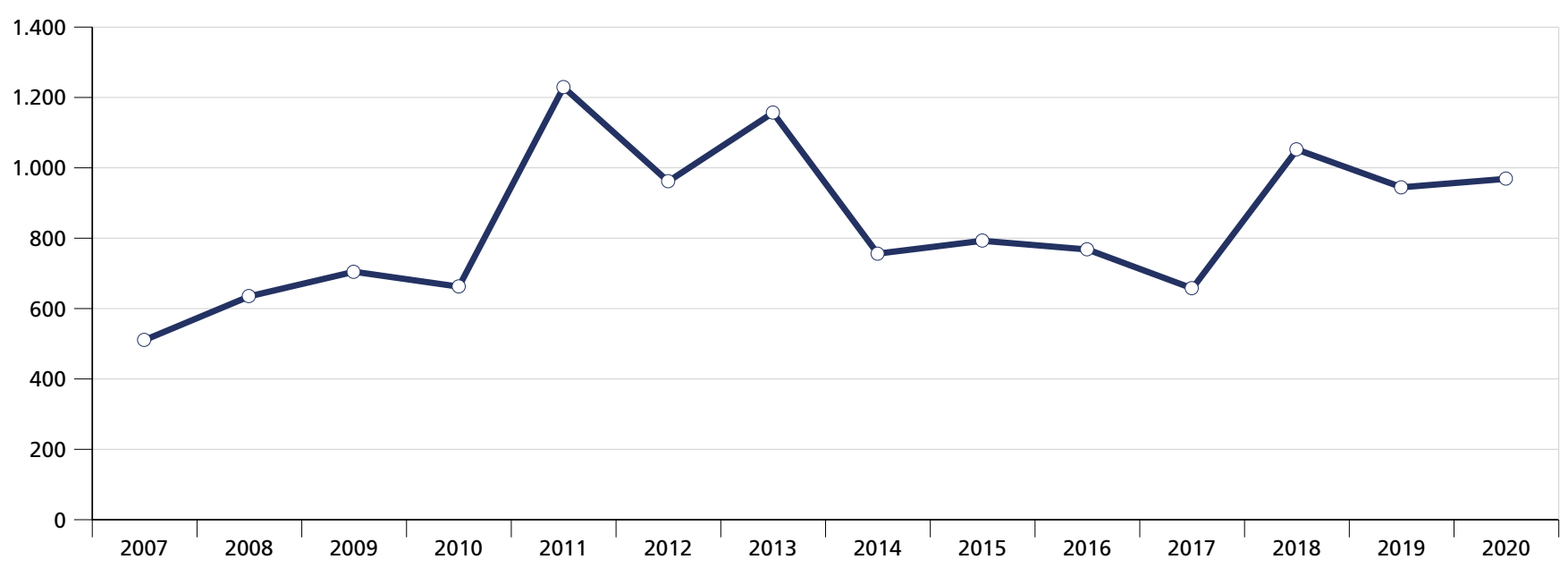

Fonte: Dados dos relatórios gerenciais do FAT e estimativas calculadas pelo BNDES. 


\section{CONSIDERAÇÕES FINAIS}

Desde sua criação até 2020, o FAT tem desempenhado um relevante papel no amparo e na geração de oportunidades de emprego e renda aos trabalhadores e às empresas, especialmente na consolidação de uma política de financiamento aos programas de desenvolvimento econômico no Brasil por intermédio do FAT Constitucional. Esse mecanismo permite ao BNDES atuar de forma livre, segura, regular e constante, apoiando empresas públicas e privadas em projetos de desenvolvimento econômico em diversos setores, com destaque à infraestrutura.

Dos dados aqui levantados, vale destacar que, entre 2002 e abril de 2021, aproximadamente $70 \%$ de todas as contratações não automáticas apoiadas pelo BNDES tiveram participação integral ou parcial dos desembolsos repassados às empresas por meio dos empréstimos. Estima-se também que o FAT Constitucional gerou/manteve algo em torno de 12 milhóes de empregos entre 2007 e 2020.

\section{REFERÊNCIAS}

BNDES - BANCO NACIONAL DE DESENVOLVIMENTO ECONÔMICO E SOCIAL. Relatório anual 2020. Rio de Janeiro: Departamento de Comunicação/Gabinete da Presidência, maio 2021.

MONTEIRO NETO, A. (Coord.). Brasil em desenvolvimento 2011 - Estado, planejamento e políticas públicas. Brasília: Ipea, 2012. v. 2.

NAJBERG, S.; IKEDA, M. Modelo de geração de emprego: metodologia e resultados. Rio de Janeiro: BNDES, 1999. (Texto para Discussão, n. 72).

PROCHNIK, M.; MACHADO, V. Fonte de recursos do BNDES 1995-2007. Revista do BNDES, Rio de Janeiro, v. 14, n. 29, p. 3-34, jun. 2008.

SANTOS, L. O. Recursos do FAT e empregos gerados ou mantidos: estimativas para a atuação do BNDES entre 1996 e 2017. Revista do BNDES, Rio de Janeiro, v. 25, n. 50, p. 99-137, dez. 2018.

SANTOS, V. M. Por dentro do FAT. Revista do BNDES, Rio de Janeiro, v. 13, n. 26, p. 3-14, dez. 2006.

SILVA, S. P. Capacidades estatais para o financiamento do investimento no Brasil: uma análise da relação institucional de complementaridade entre FAT e BNDES. Brasília: Ipea, nov. 2019. (Texto para Discussão, n. 2525).

TINOCO, G.; BORÇA JUNIOR, G. R.; MACEDO, H. F. Fundo de Amparo ao Trabalhador (FAT): breve histórico, condiçóes atuais e perspectivas. Revista do BNDES, Rio de Janeiro, v. 25, n. 50, p. 139-202, dez. 2018. 